\title{
EL GRADO CERO DE LA MUERTE EN LAS POÉTICAS DE WALT WHITMAN Y PABLO NERUDA
}

\author{
Sergio Pizarro Roberts \\ Universidad de Playa Ancha \\ Valparaíso, Chile \\ sergioto.pizarro@gmail.com
}

\section{RESUMEN /ABSTRACT}

Sobre la base del tratamiento dado a la poesía moderna en el ensayo El grado cero de la escritura, de Roland Barthes, este trabajo propone un diálogo entre las respectivas acepciones de la muerte contenidas en la obra poética de Walt Whitman y Pablo Neruda que permite concluir, comparativamente, que en ambos casos sus obras contienen una poética escatológica heterodoxa (con respecto a la tradición occidental cristiana al asumir rasgos panteístas) y soteriológica (destinada a salvar a la humanidad), pero que difieren en cuanto al idealismo teísta que se percibe en el itinerario poético whitmaniano con respecto al materialismo ateísta nerudiano.

Palabras clave: Whitman, Neruda, panteísmo, teísmo, muerte, escatología heterodoxa.

\section{Death degree zero in the poetics of Walt Whitman and Pablo Neruda}

On the basis of the treatment given to modern poetry in the essay Writing Degree Zero, by Roland Barthes, this work proposes a dialogue between the respective meanings of death contained in the poetic work of Walt Whitman and Pablo Neruda. This dialogue allows us to conclude, comparatively, that in both cases their works contain a heterodox eschatological poetics (regarding the Western Christian tradition, when assuming pantheistic features) and soteriological poetics (destined to save humanity), but they differ in the theistic idealism that is perceived in Whitman's poetic itinerary in regard to Neruda's atheist materialism.

KEYWORDS: Whitman, Neruda, pantheism, theism, death, heterodox eschatology.

Recepción: 11/09/2018

Aprobación: 18/11/2019 


\section{INTRODUCCIÓN. ACERCA DE LA MUERTE EN LA POESÍA MODERNA}

Roland Barthes (1915-1980), en la sección titulada "¿Existe una escritura poética?" de su ensayo El grado cero de la escritura (1953), sostiene que en la poesía moderna, a diferencia de lo que ocurre con la poesía clásica,

las palabras producen una suerte de continuo formal del que emana poco a poco una densidad intelectual o sentimental imposible sin ellas; la palabra es el tiempo denso de una gestación más espiritual, durante la cual el "pensamiento" es preparado, instalado poco a poco en el azar de las palabras. Esta suerte verbal, de la que caerá el fruto maduro de una significación, supone entonces un tiempo poético que ya no es el de una "fabricación", sino el de una aventura posible, el encuentro de un signo y de una intención $(48,49)$.

Del encuentro aventurero "de un signo y de una intención" resulta, en la poesía moderna, una potencial resignificación del lenguaje. Según este autor, la poesía clásica, en cuanto variación ornamental de la prosa, en cambio, no configura un lenguaje diferente. La función del poeta clásico, sentencia, "no es la de encontrar palabras nuevas, más densas o deslumbrantes, es la de ordenar un protocolo antiguo" (50). En ese entendido, la poesía moderna coacciona al lenguaje. Obliga a las palabras a evocar su original estado polisémico en un ejercicio retroactivo que las sitúa en el "grado cero de la escritura", provocándole con ello una nueva potencialidad semántica que la poesía clásica no les confería. En definitiva, para Barthes el lenguaje de los poetas modernos, lejos de la función social del lenguaje clásico que se extiende hacia otras palabras en provecho de las relaciones y los vínculos, asume a la poesía como "el esplendor y la frescura de un lenguaje soñado" (56) que busca sumergirse "en una realidad interna consustancial a su designio" (49).

Por ende, la muerte, desde la perspectiva de la poesía moderna, es una palabra que encierra una inacabable potencialidad poética. Se trata de una realidad metafísica que sobrepasa las capacidades representativas del lenguaje, ya que todo discurso que intente ofrecer una explicación de lo que acontece en ultratumba conduce a respuestas que no admiten comprobación empírica. La muerte, por esa misma razón, deriva en una abstracción del pensamiento que ofrece una amplísima gama de posibilidades para el imaginario poético.

La potencialidad resignificativa que el lenguaje de la poesía moderna, según Barthes, le confiere a las palabras y la polisemia inherente al concepto 
de muerte, nos avala en el intento de problematizar su tratamiento poético contemporáneo, que no es otra cosa que alcanzar el grado cero del lenguaje escatológico y acceder, por consecuencia, al más amplio abanico de sus posibilidades semánticas.

Para Barthes, sin embargo, la poesía moderna surge con Rimbaud en una comprensión restrictiva que limita la mayor extensión que podría aplicársele a su dispositivo teórico. En efecto, Octavio Paz (1914-1998) discute (no directamente) en su ensayo Los hijos del limo (1972), con la cronología dispuesta por Barthes al señalar que la poesía moderna nace, no con Rimbaud, sino antes, con el romanticismo inglés y alemán de fines del siglo XVIII y principios del XIX; que continúa en el simbolismo francés y luego en el modernismo hispanoamericano para culminar en las vanguardias de principios del siglo XX.

Según el autor mexicano, los poetas que integran las tendencias revolucionarias del romanticismo adoptan una posición de ambigüedad ante la religión cristiana de Occidente. Son poetas con intensas inquietudes metafísicas cuyas perspectivas espirituales, sin embargo, escapan a una clasificación religiosa tradicional. Rescata los ejemplos de Hölderlin y su divinidad solar, la Virgen de Novalis y su Noche precristiana, las creencias heteróclitas de Blake, las divinidades paganas en Nerval, el ateísmo de Shelley, la Pantisocracia de Coleridge, etc. Ejemplos todos que le permiten concluir que el pensamiento romántico se caracteriza por sus "herejías, sincretismos, apostasías, blasfemias y conversiones" en donde "cada poeta inventa su propia mitología" (53).

$\mathrm{Al}$ aplicarles, en consecuencia, la categoría teórica moderna de Barthes a los poetas románticos se comprueba su acceso al grado cero de la escritura en cuanto configuran diversas resignificaciones de la muerte que escapan a su acepción convencional y que finalmente redundan en poéticas escatológicas heterodoxas en relación con la tradición occidental cristiana.

Walt Whitman (1819-1892) no se encuentra en el listado de poetas románticos de Los hijos del limo, por una razón que el mismo Paz da en su otro ensayo El arco y la lira, en el lugar preferente que le otorga en el tercer y último apéndice titulado: "III. Whitman, poeta de América". A diferencia de los poetas románticos paradigmáticos antes señalados, allí Paz señala que "Walt Whitman es el único gran poeta moderno que no parece experimentar inconformidad frente al mundo" (297); aseveración importante para nuestro acercamiento a la poética escatológica del autor norteamericano desde que su poesía confiere una inédita resemantización de la muerte que la traduce a vida, opacando el sentido destructivo que subyace a dicho concepto. 
La particular utopía que inspira la obra poética de Walt Whitman y la original concepción tanatológica que ella contempla, ha llevado al crítico Harold Bloom a incluirlo dentro de lo que él considera como el canon de literatura occidental. Lo designa como el gran profeta religioso norteamericano cuando sostiene que "cualquier consideración de la muerte en nuestra literatura nacional siempre nos lleva de nuevo a Walt Whitman" (298). Bloom nos confirma que la obra del neoyorkino califica como una poética heterodoxa al agregar que

Whitman es un gran poeta religioso, aunque la religión sea la religión norteamericana y no el cristianismo, al igual que el postrascendentalismo de Emerson es poscristiano. Al igual que en Thoreau, en Whitman encontramos la huella del Bhagavad-gita, pero la visión hindú es contemplada a través del hermetismo occidental, con sus elementos neoplatónicos y gnósticos (299).

El poeta chileno Pablo Neruda (1904-1973), incluido también en el canon occidental de Bloom, en su libro Nuevas odas elementales (1955), contiene el poema "Oda a Walt Whitman" del que rescato los siguientes versos:

Yo no recuerdo / a qué edad, / ni dónde, / si en el gran Sur mojado / o en la costa / temible, bajo el breve / grito de las gaviotas, / toqué una mano y era / la mano de Walt Whitman: / pisé la tierra / con los pies desnudos, / anduve sobre el pasto, / sobre el firme rocío / de Walt Whitman. / [...] / tú / me enseñaste / a ser americano / [...] / Pero no sólo / tierra / sacó a la luz / tu pala: / desenterraste / al hombre, / y el / esclavo / humillado / contigo, balanceando / la negra dignidad de su estatura, / caminó conquistando / la alegría. (Antología 196, 197, los énfasis son míos)

Este texto de homenaje testimonia la fuerza que le imprime el poeta de Nueva York al trabajo telúrico del poeta de Temuco. La panacea americana habría recorrido en cien años (de 1855 a 1955) todo el continente desde el extremo norte, en Long Island, hasta el confín del sur chileno. El sello mesiánico que el tratamiento de la muerte impregna a la obra poética de Whitman es traducida a una poética escatológica de similares magnitudes en el vasto iter poético nerudiano. Se trata, en ambos casos, de una poética soteriológica llamada a salvar al hombre, a "desenterrarlo" de su humillación para conquistar definitivamente su alegría espiritual, con una gran diferencia que va desde un idealismo teísta whitmaniano al materialismo ateísta nerudiano, itinerario metafísico que será el objeto de nuestra investigación comparada. 
El crítico Alain Sicard, en un poético gesto comparatístico, publica en la revista Anales de Literatura Chilena, en el año 2010, su texto "Camerado Neruda (apuntes sobre Walt Whitman y Pablo Neruda)" en cuyas 36 secciones se plasman paralelos, similitudes y diferencias entre la persona y la obra de ambos poetas americanos. Cito la última:

36. Eufemización de la muerte (¿otra cosa es la poesía?). En un verso maravillosamente intraducible, Whitman celebra que «the sure-enwinding arms of cool-enfolding death». Para el Neruda de los últimos poemas, «no hay albedrío para los que somos/ fragmento del asombro.../...ya no hay más estrella que el mar».

¿Existe un materialismo de la consolación? (192).

\section{WALT WHITMAN. LA MUERTE VIVÍFICA ${ }^{1}$}

La muerte y la vida son conceptos que pertenecen a campos semánticos opuestos y la alteración o mezcla de dicha dualidad termina indefectiblemente en aporía o paradoja. El cristianismo es una religión occidental que altera dicha dicotomía al resignificar el concepto de muerte. Para esta creencia, la relación binaria de vida y muerte encuentra su punto de oposición semántica, no en el momento de la extinción física del cuerpo y su posterior degradación, sino que en el momento en que se produce el quiebre con Dios. De esta

\footnotetext{
En atención a los marcos conceptuales de este trabajo mencionaré sintéticamente algunos de los aspectos de forma y fondo que hacen tan característica la obra poética de Walt Whitman y que están latamente contenidos en la crítica canónica escrita en relación con el poeta. Destacan el uso inédito del verso libre y su tono coloquial (Basil de Selincourt); su poesía instantánea del presente inmediato y sin consumación ni término (D.H. Lawrence); poeta de Norteamérica, pero enfáticamente de una Norteamérica que ya no existe (T.S. Eliot); poesía de propaganda (Amy Lowell); epopeya de la democracia de América (Borges); y uso del recurso musical de la reanudación -reprise- en virtud del cual la primera parte de un poema se repite con algunas diferencias en la segunda, confiriendo, según Helen Vendler, una percepción más intelectual de la realidad por parte del poeta a través de un ejercicio retórico que contradice la caracterización primitivista generalmente atribuida a la obra de Whitman. Los textos principales de consulta son: Walt Whitman, a critical anthology, editado por Francis Murphy; Introducción a la literatura norteamericana, de Jorge Luis Borges; y Poets thinking, de Helen Vendler, entre otros.
} 
manera quien, en vida, se encuentra alejado de Dios está realmente muerto $\mathrm{y}$, a la inversa, quien ha muerto en la gloria de Dios estará vivo eternamente ${ }^{2}$.

Whitman, en su obra Hojas de hierba, en particular en el texto "Canto de mí mismo", adopta el tenor salvífico del mensaje cristiano y carga su poética con un tratamiento escatológico en el que la vida anula a la muerte en su relación antagónica. Oigamos los cantos seis, siete y cuarenta y nueve ${ }^{3}$ :

Canto 6.

[...]

El retoño más débil prueba que no existe la muerte

Y que si alguna vez existió lo hizo para impulsar la vida, y no espera que lo destruya al fin,

Y cesó ${ }^{4}$ en el momento en que surgió la vida.

Todo progresa y se dilata, nada se viene abajo,

Y morir es algo distinto de lo que muchos supusieron, y de mejor augurio

(35, la cursiva es mía).

Canto 7.

¿Ha pensado alguien que es afortunado nacer?

Me apresuro a informarle que no es menos afortunado morir, y sé lo que digo (35).

Canto 49.

Y en cuanto a ti, Muerte, y a ti, amargo abrazo mortal, es inútil que

2 Cito el Nuevo Diccionario de Teología: "para los cristianos [...] la muerte representa la transición entre la forma de vida física que se extingue con ella y el comienzo de una nueva forma de vida" (655). Según esta fe, no se considera a la muerte "como un fenómeno biológico, sino teológico, [ya que] siempre que la persona humana rompe su relación con Dios, [...] abandona la raíz de su vida y cae en la muerte" (658).

3 En este trabajo he utilizado el texto bilingüe titulado Hojas de hierba editado por Lumen, en 1997, con selección, traducción y prólogo de Jorge Luis Borges.

$4 \quad$ La traducción de Borges reza: "no ha cesado" que puede deberse a algún error de imprenta. El texto en inglés señala: They are alive and well somewhere, / The smallest sprout shows there is really no death, / And if ever there was it led forward life, and does not wait at the end to arrest it, / and ceas'd the moment life appear'd. (34). Considero que la traducción más adecuada, y acorde al contenido del poema, es que la muerte "cesó" en el momento en que surgió la vida en vez de la traducción sugerida por Borges de que la muerte "no ha cesado" en ese momento. 
trates de asustarme. [...]

Y en cuanto a ti, Vida, pienso que eres la herencia de muchas muertes, (Sin duda he muerto ya diez mil veces) (165).

Además de varios cantos en el que se refiere a su inmortalidad (cantos 7, 20, 42,43 y 46), se constata que el hablante whitmaniano da un giro radical en la relación dicotómica al sostener que no existe la muerte. Previa evocación del original estado polisémico de las palabras, el hablante se sitúa en el grado cero de la muerte y le sustrae su acepción asignada, para finalmente despotenciarla. De esta manera, en la balanza que supone la relación binaria de ambos conceptos, la vida subsume a la muerte, o dicho de otra manera, la muerte es absorbida semánticamente por la vida, transformándose paradójicamente, en muerte vivífica. El sentido destructivo que subyace a dicho concepto, en consecuencia, se ve reemplazado, en Whitman, por un vitalismo eterno. ("Me río de lo que llamas disolución, / Y conozco la amplitud del tiempo" (69), complementa el hablante en los dos últimos versos del canto 20).

En la cita transcrita del canto 49, el hablante se dirige apostróficamente a la muerte y a la vida, respectivamente, y al referirse a la vida la piensa como "heredera de muchas muertes", agregando que ha muerto ya diez mil veces. Con ello, nuevamente, se debilita la carga destructiva de cada una de esas miles de muertes para aludir a un circuito rotativo en el que dichas muertes no son más que modificaciones cíclicas dentro de una misma vida eterna. En ello se diferencia del discurso cristiano por cuanto en este último hay una sola vida eterna o una sola muerte que es definitiva, en cambio, en la poética escatológica whitmaniana no hay espacio para la muerte rotunda; se postula una sola vida y un sinnúmero de muertes irrelevantes que solo implican transformaciones dentro de una permanente unidad vital que Whitman cataloga como el Alma:

\section{Canto 48.}

Dije que el alma no es más que el cuerpo,

Y dije que el cuerpo no es más que el alma,

Y que nada, ni Dios, es más que uno mismo [...]

Y digo a cualquier hombre o mujer: Que tu alma esté serena y en paz ante millones de universos. [...]

(No hay palabras capaces de expresar mi seguridad ante Dios y la muerte).

Escucho y veo a Dios en cada cosa $[\ldots](161,163)$. 
Al tenor de estos versos es indudable la fisonomía teísta de la poética escatológica del escritor norteamericano, pero con características que la alejan de la tradición cristiana. Esta última creencia postula una realidad en la que coexisten la dualidad de un ser creador (Dios) y un ser creado (hombre/mujer). El Dios al que se refiere el hablante whitmaniano, en cambio, escapa a dicha referencia dual (creador/creado) y se acerca a una concepción panteísta de la realidad en la que todo es Dios (pan: todo; theos: Dios) ${ }^{5}$. Si todo está en Dios y Dios está en todo se diluye la relación dual entre creador y creado. Dios ‘no es más que uno mismo', dice el verso citado y 'Dios está en todas las cosas', refiere el último. El sujeto whitmaniano y la humanidad completa es Dios como también lo son todos los objetos y el universo circundante. $\mathrm{Si}$, como señala la definición de panteísmo transcrita, toda la realidad está unida de algún modo, el gran todo no sería más que una sola Alma Universal, común a todos los hombres de todos los tiempos, con lo cual se comprende aún más la reiterada idea de inmortalidad en los cantos antes señalados ${ }^{6}$.

Esta propuesta no es exclusivamente metafísica desde que conlleva la construcción de una nueva y concreta subjetividad mixta, es decir, que es individual pero colectiva a la vez, ya que toda la humanidad se encuentra unida a una esencia común con simples variedades en las apariencias. Así, Dios está presente en cada uno de los seres humanos que, en realidad, es un solo hombre pero fragmentado, y no es irrelevante que, según Whitman, no exista la muerte porque cuando una persona muere, el Alma Universal continúa en otra, dentro de una unidad orgánica y espiritual a la que todos pertenecen ${ }^{7}$.

\footnotetext{
Panteísmo: “concepción según la cual Dios es idéntico a todo. Puede verse como el resultado de dos tendencias: un intenso espíritu religioso y la creencia de que toda la realidad está unida de algún modo. [...] Spinoza es el panteísta más distinguido de la filosofía occidental. Argumenta que puesto que la sustancia es completamente autosuficiente y solo Dios es autosuficiente, Dios es la única substancia. En otras palabras, Dios es todo. Hegel también es a veces considerado panteísta, puesto que identifica a Dios con la totalidad del ser [...]”. (Diccionario Akal de Filosofía 733, en línea).

D.H. Lawrence, en su artículo "Whitman" (1921), señala: "At last all is one, all is love, even hate is love, even flesh is spirit. The great oneness, the experience of infinity, the triumph of the living spirit, which at last includes everything, is here accomplished" (Lawrence en Murphy, 198).

No debe confundirse este planteamiento con la antigua doctrina de la metempsicosis, que da lugar a la teoría de la reminiscencia en Platón, y que postula el tránsito del alma desde un individuo a otro, con lo cual supone la existencia de un sinnúmero de almas separadas (Fedón 108). El panteísmo de Whitman, en cambio, no alude a diversas almas deambulando
} 
Si la muerte no existe, tampoco existen los nacimientos desde que la humanidad es un flujo que transita a través de esta gran unidad espiritual que es el Alma Universal, la cual entra y sale de la vida biológica de cada individuo en un continuum de ciclos que se suceden eternamente. Whitman profesa esta creencia cuando declama

\section{Canto 44 .}

$[\ldots]$

Soy un ápice de las cosas cumplidas y contengo las cosas que serán [...]

Veo en el fondo la vasta Nada primordial, y sé que estuve allí,

Yo esperaba siempre, invisible, durmiendo en la bruma letárgica, [...]

Mucho tiempo la sombra me cobijó [...]

Inmensa fue la preparación de mi ser, $[\ldots]$

Antes de que yo naciera de mi madre, las generaciones me guiaron, Mi embrión no durmió nunca, nada pudo oprimirlo (149).

La influencia del idealismo trascendentalista del ensayista norteamericano Ralph Waldo Emerson (1803-1882) en Whitman es evidente desde la publicación, en 1836, de su breve ensayo Naturaleza ${ }^{8}$. En dicha obra se postula una triangulación en la que intervienen Dios, la naturaleza y el hombre que redunda, finalmente, en la divinización de este último. Según Emerson

[1]a naturaleza es el órgano a través del cual el espíritu universal habla al individuo, y lucha por reconducir al individuo hacia él. $[\ldots]$ el espíritu crea $[\ldots]$ no actúa en nosotros desde fuera $[\ldots]$ sino espiritualmente, o a través de nosotros mismos [...] el Ser Supremo, no crea la naturaleza a nuestro alrededor, sino que la extiende a través de nosotros [...] así el hombre descansa en el seno de Dios; es alimentado por fuentes que no se secan jamás $(105,107)$.

\footnotetext{
sucesivamente a través de los individuos sino que postula la existencia de una sola alma que se divide y reparte entre todos los individuos.

$8 \quad$ Según Jorge Luis Borges, a partir de la fecha de publicación de Naturaleza, en 1836, florece durante un cuarto de siglo el trascendentalismo en América, e informa que sus fuentes fueron múltiples: "el panteísmo hindú, las especulaciones neoplatónicas, los místicos persas, la teología visionaria de Swedenborg, el idealismo alemán y los escritos de Coleridge y Carlyle" (35).
} 
El espíritu del hombre determina las potencias de la naturaleza y cuando eso ocurre, el Ser Universal circula a través de su cuerpo y se convierte en partícula de Dios. A través de la naturaleza, dice Emerson, "[m]e convierto en un globo ocular transparente, no soy nada, veo todo, las corrientes del Ser Universal circulan a través de mi cuerpo, soy una parte o partícula de Dios" (31), aseveración que refleja un misticismo panteísta común con la poética escatológica de Walt Whitman. "Nada es hermoso salvo en el todo" (48) continúa Emerson y, en concordancia con el discurso del hablante whitmaniano recalca: "[n]ada divino muere. Todo lo bueno se reproduce eternamente. La belleza de la naturaleza se reproduce en la mente, y no para la contemplación estéril, sino para dar paso a una nueva creación" (47). Por ende, si la naturaleza deifica al hombre, la muerte no existe para él.

Sin embargo, este proceso de divinización, para Emerson, no es automático ya que depende de la voluntad del hombre para que opere:

Toda criatura racional tiene la naturaleza entera como dote y herencia. Es suya si él la quiere. Puede deshacerse de ella, puede retirarse a un rincón y abdicar de su reino, como hace la mayor parte de los hombres, pero por su constitución tiene derecho al mundo. Según sea la energía de su pensamiento y voluntad, asumirá el mundo en sí mismo $(43,44)$.

Asume el autor que "la mayor parte de los hombres" no hará uso de esta potencialidad y que, por lo tanto, la salvación que redunda en vida eterna, favorecerá solo a unos pocos (punto en el cual se aleja del discurso más universal de Whitman). En la última sección de su ensayo asegura que el hombre contemporáneo aplica a este afán divinizante de la naturaleza tan solo la mitad de sus fuerzas y que debe catalogársele peyorativamente como un "semihombre". Acota que "su mente está embrutecida, es un salvaje egoísta" (119), por lo que está lejos del proceso de salvación teorizado en el referido ensayo y cantado por Whitman. Se trata de un mensaje soteriológico restrictivo, heredero del movimiento clerical conocido como unitarianismo que transformó a la mentalidad calvinista puritana. El académico mexicano Sergio Cervantes explica que

[u]na de las manifestaciones más importantes del romanticismo en los Estados Unidos fue el que se produjo en el ámbito religioso y que se 
conoció como unitarianismo. [...] Según Parrington ${ }^{9}$, el unitarianismo fue una diseminación de las ideas liberales de la Francia del siglo XVII sobre la conciencia conservadora de las élites de Boston. El unitarianismo consideraba a la humanidad virtuosa en sí misma, pero corrompida por las instituciones sociales, y por lo tanto creían en la perfectibilidad del hombre como individuo (178).

Por lo tanto, podemos argüir, en los términos de Octavio Paz, que el pensamiento emersoniano y la poética whitmaniana comparten las tendencias revolucionarias del romanticismo con una postura de ambigüedad ante la religión cristiana de Occidente que delata la invención de su propia mitología. En concreto, Canto de mí mismo, de Walt Whitman, revela un poemario idealista y teísta en el cual la figura de Dios tiene un protagonismo tal que sus características permiten situar dicha obra poética más bien alejada de la tradición occidental cristiana y cercana a una vertiente panteísta, todo lo cual permite finalmente calificarla como una poética escatológica heterodoxa ${ }^{10}$.

\section{PABLO NERUDA. LA MUERTE SEMINAL}

Aunque Neruda implica, las más de las veces, hablar de amor y compromiso político, su obra poética también confiere lugar protagónico al tema de la muerte ${ }^{11}$. Un poema, dentro de una revisión diacrónica de su obra, que aporta elementos escatológicos sustantivos para el análisis comparado con la obra de Whitman, es aquel titulado "Significa sombras", de Residencia en la Tierra (1935), cuyo extracto transcribo:

Ay, que lo que yo soy siga existiendo y cesando de existir [...] que el temblor de las muertes y de los nacimientos no conmueva el profundo sitio que quiero reservar para mí eternamente.

9 Vernon Louis Parrington, crítico literario norteamericano (1871-1929).

10 El carácter heterodoxo de la estética escatológica de Whitman bordea incluso la herejía cuando el hablante se asimila a la figura de Cristo en el canto 38: "Si yo pudiera mirar con indiferencia mi propia crucifixión y mi coronación de espinas" (129).

11 Alain Sicard, en su monografía crítica El pensamiento poético de Pablo Neruda, asevera que "la metafísica [es] una constante de su poesía" (9). 
Sea, pues, lo que soy, en alguna parte y en todo tiempo, establecido y asegurado y ardiente testigo, cuidadosamente destruyéndose y preservándose incesantemente, evidentemente empeñado en su deber original. (101, 102, los énfasis son míos)

En este poema es evidente la semejanza del ejercicio resemantizador de la muerte en ambos poetas americanos. Neruda, en los términos de Roland Barthes, coacciona al lenguaje y obliga a la palabra muerte a un ejercicio retroactivo que la sitúa en el grado cero de la escritura. Evoca su original estado polisémico y le provoca, en consecuencia, una nueva potencialidad semántica similar a la que le brinda Whitman con el mismo ejercicio. El "Yo que es" sigue existiendo y cesando de existir, por lo que el ser se mantiene ontológicamente intacto en este cambio de dimensión (vida/muerte) que hipotéticamente debiera eliminarlo. El sujeto nerudiano altera, por lo tanto, la acepción tradicional de la muerte y la resignifica desde el momento en que declara su intención de existir y dejar de existir, destruyéndose y preservándose "incesantemente". Al igual que el sujeto whitmaniano, el nerudiano le sustrae a la muerte su carácter destructivo y el cruce de dicho sujeto a la frontera entre ambos campos semánticos tiene como consecuencia que la vida adquiere una poderosa carga vivífica que la capacita para absorber a la muerte, resemantizándola.

Amado Alonso, en su ensayo crítico Poesía y estilo de Pablo Neruda (1951), aclara que es necesario distinguir entre las dos etapas residenciarias y que en la primera parte de dicha obra "la visión del mundo no es de desintegración ni la disposición psíquica es propiamente de angustia, y si hay desintegración, ésta es el escenario, el aire y el campo por entre cuyos lentos escombros renace a cada instante el espíritu indestructible" (24, énfasis mío). El poema "Significa sombras" es el último de esta primera parte y acuña efectivamente el concepto de un "espíritu indestructible" o que al menos se destruye y reconstruye cíclicamente y que mantiene un lugar, "un profundo sitio", que el sujeto residenciario quiere "reservar para sí eternamente". Con ello se matiza la angustia desolada que traspasa toda la obra residenciaria y se asoma un replanteamiento de la muerte que desconfigura su acepción tradicional terminal y revela, en términos similares a Whitman, una profunda inquietud metafísica.

El crítico Jaime Concha rescata ese carácter metafísico que subyace a la obra nerudiana; más precisamente, la angustia metafísica gatillada por la 
falta de sentido en donde, según él, "el poeta sufre un Apocalipsis sin Dios" (en línea). Esta última aseveración importa comparativamente porque la obra de Whitman, como tuvimos oportunidad de comprobar, contiene una poética teísta, ya que contempla la presencia de Dios, y que, además, se acerca a una concepción panteísta de la realidad. Neruda, en cambio, excluye la participación de Dios en su cosmogonía, revelando una poética ateísta.

Para comprender mejor esta diferencia es necesario señalar que, según el Diccionario de filosofía de José Ferrater Mora, el panteísmo es una corriente de pensamiento según la cual la naturaleza y la deidad que suele llamarse Dios son la misma entidad a la que pertenece el hombre y todo lo existente. Para este pensamiento, la ley natural, el universo y todo lo que existe en él son representados a través del concepto teológico que la humanidad les ha asignado con el nombre de "Dios". El panteísmo asume, sin embargo, dos variantes: aquella que considera a la naturaleza y al mundo como emanación de Dios, según la cual, la realidad divina es la única realidad verdadera y a ella se reduce el mundo, y la otra, que concibe a la naturaleza como la única realidad verdadera y que, a la inversa, Dios se reduce a ella. La diferencia entre ambas es que la primera versión cree en una jerarquía superior de Dios, por lo que puede considerarse como panteísmo teísta, en cambio, la segunda no cree en dicha jerarquía metafísica por lo que suele denominarse panteísmo ateo o naturalista. En ambos casos se postula que no hay ninguna realidad trascendente ya que todo es inmanente. Si tanto Whitman como Neruda disuelven la dicotomía entre vida y muerte se hace irrelevante hablar de trascendencia porque todo sucede en un ahora instantáneo y eterno que nos hace inmanentes ${ }^{12}$. Así, Whitman adopta una poética teísta que contempla la presencia de Dios aunque sea en su versión heterodoxa panteísta y Neruda, en cambio, excluye la participación de Dios en su cosmogonía, lo cual revela una poética ateísta aunque también panteísta, en su versión naturalista.

En la temática de la muerte desarrollada en Canto general (1950), debemos distinguir entre el cúmulo de muertes insulsas que el sujeto nerudiano impide que caigan en el olvido y la resignificación de esas muertes por las

12 D.H Lawrence, en su artículo "Poetry of the Present", sostiene: "There is poetry of this immediate present, instant poetry, as well as poetry of the infinite past and the infinite future. [...] Whitman's is the best poetry of this kind. Without beginning and without end. [...] The clue to all his utterance lies in the sheer appreciation of the instant moment, life surging itself into utterance as its very well-head. Eternity is only an abstraction from the actual present. [...] This is the immanence" (Lawrence en Murphy 193). 
que intercede dicho sujeto lírico. En el primer caso, el hablante denuncia las injusticias y mezquindades de la historia y en el mismo gesto absorbe todas las pequeñas muertes que canta. Sin la participación lírica de su canto, esas "pequeñas muertes" (todas nuestras pequeñas muertes) habrían sido inútiles. El timbre de su voz (heredero de Whitman), es mesiánico y soteriológico. Esta tonalidad se percibe claramente en el capítulo II "Alturas de Macchu Picchu" de cuya parte final destaco: "Yo vengo a hablar por vuestra boca muerta. [...] / Acudid a mis venas y a mi boca. / Hablad por mis palabras y mi sangre" $(42,43)$.

El carácter panteísta de la poética en Canto general se comprueba en el uso reiterado por parte del hablante del recurso metafórico de la semilla. Abundan referencias a semillas que caen a la tierra para luego germinar; de semillas esperando a la primavera; de paz germinadora; de la semilla del hombre, etc. ${ }^{13}$. El hombre, una vez muerto, no es sino semilla que brota desde la arena dentro de un itinerario que no escapa a lo inmanente. De esta manera, por ejemplo, el hablante rescata a Martí que "está en el fondo circular del aire, / está en el centro azul del territorio, / y reluce como una gota de agua / su dormida pureza de semilla" (139). Desde la "arena americana", por su parte, el poeta dice:

No me siento solo en la noche, en la oscuridad de la tierra.

Soy pueblo, pueblo innumerable.

Tengo en mi voz la fuerza pura para atravesar el silencio y germinar en las tinieblas.

Muerte, martirio, sombra, hielo, cubren de pronto la semilla.

Y parece enterrado el pueblo.

Pero el maíz vuelve a la tierra.

Atravesaron el silencio

sus implacables manos rojas.

Desde la muerte renacemos (343).

El último capítulo de Canto general, titulado "Yo soy", remata: 


\author{
Compañeros, enterradme en Isla Negra, $[\ldots]$ \\ saben \\ que allí quiero dormir entre los párpados \\ del mar y de la tierra... \\ Quiero ser arrastrado \\ hacia abajo en las lluvias que el salvaje \\ viento del mar combate y desmenuza, \\ y luego por los cauces subterráneos, seguir \\ hacia la primavera profunda que renace $[\ldots]$ (477).
}

El profesor Hernán Loyola, en un estudio relativo al poema "Alturas de Macchu Picchu", concluye: "Neruda reafirmó su intuición de la muerte como una fuerza viva dentro del gran ciclo cósmico [con un sujeto] inscrito en las repeticiones y regresos del tiempo circular". Y agrega que en el poema

[n]o existe [la muerte] con las connotaciones siniestras y temibles, con aquel aura terrorífica que los hombres le asignan, o que se han visto obligados a asignarle a lo largo de la historia. No existe simplemente porque aquello que los hombres padecen y llaman Muerte es sólo una fase integrante e indistinguible dentro del más grande amor, forma parte de él, es condición necesaria. La muerte no es tragedia en el seno del más grande amor (En línea).

La afirmación de Loyola parece ser una evocación del verso "no existe la muerte" de Whitman citado anteriormente y devela la íntima sintonía que Neruda mantiene con el poeta norteamericano.

La paradoja de una muerte vivífica en Whitman y seminal en Neruda se representa en ambos registros poéticos con la reasignación semántica que anula su carga destructiva (en su moderno grado cero). En Whitman ya lo habíamos constatado en el canto 49 cuando se refiere a la vida como heredera de muchas muertes, es decir, un sinnúmero de muertes irrelevantes que solo implican transformaciones dentro de una permanente unidad vital que las subsume. Esta misma proliferación de muertes abunda en el poema "Alturas de Macchu Picchu" que estudia Mario Rodríguez cuando rescata, entre otras alusiones, a la 'pequeña muerte', a la 'muerte propia' y a la 'poderosa muerte'. El crítico sentencia que "la muerte es absorbida por una vida total que se despliega ininterrumpidamente en torno al yo" (42) y agrega que "[h] ay por sobre la muerte y el tiempo una permanencia de vida posible de ser recuperada en cuanto uno se sienta solidario, hermano del otro" (44). Con ello se confiere una explicación social al fenómeno semántico nerudiano 
para concluir que es el amor fraternal entre los hombres el que da el poder a la vida para avasallar y hacer retroceder a la muerte ${ }^{14}$.

En las obras posteriores de Neruda, en particular en Nuevas odas elementales (1955), Estravagario (1958), Navegaciones y regresos (1959) y Cien sonetos de amor (1959), se percibe un tránsito desde el tono del sujeto residenciario a un hablante que el poeta llama "el hombre invisible": "[Y]o me río, / me sonrío / de los viejos poetas / [...] / siempre dicen "yo" / [...] / y sólo yo no existo / yo soy el único / invisible" (Nuevas odas elementales, Antología 199, 201).

En Estravagario (1958) se disminuye la intensidad de la imagen poética para pasar a un mecanismo de preguntas y pensamientos metafísicos sobre la vida y la muerte; puede incluso considerarse como el permiso que se da el hablante para indagar en la contradicción y el absurdo. En nuestra línea de trabajo destaco los siguientes versos: "Cuánto vive el hombre, por fin? / Vive mil días o uno solo? / Una semana o varios siglos? / Por cuánto tiempo muere el hombre? / Qué quiere decir 'Para siempre'?” (Antología 225)'.

En Navegaciones y regresos (1959), en el poema "Soledades de la tierra china" se produce un cambio decisivo:

Y ni la muerte ni la vida

dependen de mi amor o mi canto $[\ldots]$

(El hombre chino trabaja la tierra

y la tierra china lo trabaja,

aguza sus manos pacientes,

dibuja surcos en su cara.

Luego la tierra espera al hombre

y él se confunde con el polvo

como una pálida semilla). (Antología, 246, 247, énfasis míos)

14 En relación con la lamentación elegíaca en 'Alturas de Macchu Picchu', Cedomil Goic llega a conclusiones similares pero a través de una visión hermenéutica distinta: "el metafísico cuestionarse del origen o la existencia de los poderes hostiles o destructores del universo, concluye por aceptar la ley y convertir su inconmovible y mortal eficacia en sentido positivo de la vida y la renovación [...] articulada en una concepción de la muerte ajena a la visión cristiana (160).

15 Según el crítico Carlos Cortínez, en la obra Estravagario se da "una imprevista torsión en la actitud lírica de su autor, y se atribuyó, en gran medida, a la (benéfica) influencia de Nicanor Parra y su «antipoesía»" (103). 
De los extractos citados se desprende que la tonalidad mesiánica del sujeto lírico de Residencia en la Tierra y Canto general se debilita. Se percibe el asomo de un escepticismo crítico con un sorprendente giro amnésico que prefigura la consabida versatilidad poética de Neruda. Dicho giro no significa que el hablante se aleja del discurso escatológico panteísta sino que abandona el sitial de su pedestal, ya que "ni la vida ni la muerte dependen de su canto", y en una conversión desacralizadora (anti poética) de su voz, comparte llanamente con el lector-humanidad su mirada heterodoxa de la muerte.

En su obra tardía, el giro es total. En el poema "Yo volveré" de Las piedras de Chile (1960), el tránsito del hombre residenciario al hombre invisible finaliza en un hombre "sin voz":

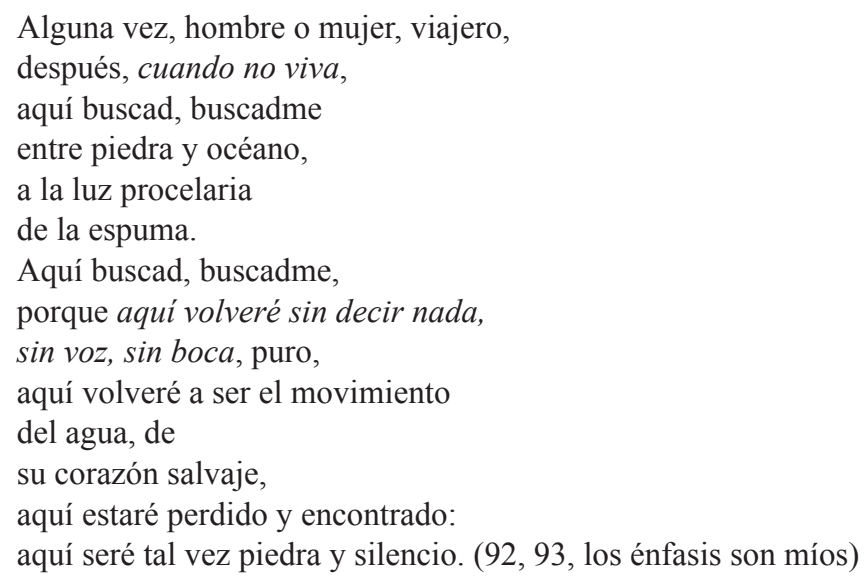

El sujeto nerudiano de Canto general se atribuye la autoridad de "hablar por nuestra boca muerta". En dicho texto las muertes de la humanidad no se ven resignificadas sino mediante la intercesión lírica del hablante que actúa en función redentora. En la obra nerudiana tardía, en cambio, la muerte no depende del canto del hablante que, finalmente termina paradójicamente mudo. En esta fase, el proceso panteísta de resignificación escatológica no requiere de ninguna participación mediadora del poeta-sacerdote. El hablante nerudiano simplemente constata el fenómeno de resemantización tanatológica y se integra armónicamente a la cadena sucesiva junto al resto de la humanidad cuando, una vez muerto (sin estarlo realmente), solicita que lo busquen en la espuma, entre piedra y océano, ya que allí 'volverá sin decir nada, sin voz y sin boca'; 'volverá a ser el movimiento del agua y estará perdido y encontrado'. 
Los últimos versos del poema "Manuela material", de Cantos ceremoniales (1961), confirman lo anterior:

Así, tal vez desnuda, paseas por el viento

que sigue siendo ahora tu tempestuoso amante.

Así existes ahora como entonces: materia, verdad, vida imposible de traducir a muerte (33).

Si Manuela "existe ahora" (estando muerta) como entonces (cuando estaba viva), más que humana es "materia, verdad" y no ficción religiosa trascendida hacia alguna dimensión imaginaria; Manuela no es pero está, incluso está aporéticamente donde no está ${ }^{16}$.

Hasta aquí, es indudable la influencia de Whitman en cuanto precursor de Neruda, particularmente en la obra tardía del poeta chileno en donde el poemario norteamericano "Canto de mí mismo" se ve mejor reflejado. Los últimos versos de dicho texto dejan de manifiesto la inmanencia de la propuesta estética que inspira al poeta chileno:

Canto 52.

[...]

Que el lodo sea mi heredero, quiero crecer del pasto que amo;

Si quieres encontrarte conmigo, búscame bajo la suela de tus zapatos.

Apenas comprenderás quién soy o qué quiero decir,

Pero he de darte buena salud, y a tu sangre, fuerza y pureza.

Si no me encuentras al principio no te descorazones,

Si no estoy en un lugar me hallarás en otro,

En alguna parte te espero (171).

Si el hablante se refiere a "herederos" es porque su discurso se proyecta a ultratumba, resignificándola, toda vez que el sujeto no trasciende ni desaparece

$16 \quad$ La "Manuela material" a la que hace mención el poema de Cantos ceremoniales es la quiteña Manuela Sáenz Aizpuru (1795-1856), reconocida solo a mediados del siglo XX como protagonista indiscutible en la historiografía independentista hispanoamericana. Para nuestra investigación interesa el tratamiento poético que le brinda Neruda, ya que el tránsito escatológico deja de ser experimentado exclusivamente por el hablante; se pluraliza y participan en dicho proceso de transformación otros sujetos al interior de los textos poéticos. 
sino que se reintegra al Todo Universal; lugar indefinido desde el cual "se espera" al resto ${ }^{17}$.

Respecto a la obra póstuma del poeta chileno, el crítico Jaime Alazraki postula que para Neruda "la poesía sería vista como un arduo proceso de desintegración a través del cual el poeta intenta desarmar el enigma de la creación, para finalmente corroborar que la esencia de su misterio es aquella "unidad donde todo participa de todo"' (Alazraki en Salerno 23). Con ello, el crítico alude claramente a la doctrina panteísta sin mencionarla. Añade que, en el esfuerzo de su poesía última, Neruda utiliza términos que son

propios de las religiones místicas de todos los tiempos, particularmente de los textos del Vedante. Neruda, al igual que los antiguos upanishad, busca en la diversidad de las formas identidades en la creación, un principio unificador, y utiliza la imagen literaria para intentar ir más allá de lo efímero y contingente. El mismo tema de la muerte es tratado, desde Las Manos del Día (1968), de manera más serena y reflexiva. Morir es entrar en un mar de claridades, en un mundo inconsciente del cual muy poco sabemos, en el cual nacer y morir se encuentran y confunden (Alazraki en Salerno 23).

En consonancia con Alazraki, el filósofo chileno Clarence Finlayson, cultor de una ensayística escatológica poco conocida en nuestro país, en el ensayo "Visión de la muerte en Pablo Neruda", coincide en que el tratamiento tanatológico del poeta sobrepasa los límites occidentales aunque, en vez de conectar su poética con los antiguos Upanishad, lo hace con el budismo. La hipótesis de Finlayson es que, desde el punto de vista metafísico, la poesía nerudiana revela el conflicto entre el deseo de inmortalidad y la Nada budista. Afirma: "[1]a expresión poética de Neruda manifiéstase vigorosa -a pesar de su desolación metafísica- por el encuentro fuerte y trágico del deseo inmortal de inmortalidad con el reposo definitivo cósmico" (185), para concluir, en definitiva, que "[p]ara coger el sentido de la muerte en la poesía nerudiana,

17 En su Antología crítica de la Nueva Poesía Chilena (1957), Jorge Elliott opina que: “el 'yo' de Whitman tiende a perder su identidad en lo multitudinario, lo que lo hace sensible a una transformación marxista. El marxista, por otra parte, va a sentir de una manera muy especial su fe democrática. Es así que un poeta que vivió al borde de la experiencia mística logra, entre nosotros, transformarse en uno de los mayores inspiradores de los poetas materialistas. No hay aquí, sin embargo, contradicción sino captación parcial de la obra de un poeta cuyo tono, además, les era adecuado" (58). 
es preciso vislumbrar el ansia de vida que vibra y palpita en cada uno de sus versos" (181). Cabe hacer presente que este ensayo fue publicado en el año 1939 por lo que las obras de Neruda que somete a su análisis no van más allá de su primera y segunda Residencia en la Tierra. Con todo, su convicción acerca del anhelo inmortal de supervivencia que subyace a la poética escatológica nerudiana (y que posteriormente incorpora la metáfora de la semilla) hace de la muerte una dimensión tan vivífica como la propuesta en la poética de Walt Whitman ${ }^{18}$.

A modo de recapitulación y conclusión, se comprobó que la poesía moderna, según Roland Barthes, posibilita una potencial resignificación del lenguaje mediante el ejercicio retroactivo hacia el grado cero de la escritura que, en nuestro caso, deriva en la problematización semántica de la muerte. Los poetas modernos Walt Whitman y Pablo Neruda, en sus respectivas poéticas escatológicas, coinciden en un planteamiento heterodoxo con respecto a la tradición occidental cristiana sobre la base de un discurso soteriológico, es decir, focalizado en la salvación del hombre y que se sustenta, precisamente, en la resemantización de la muerte al conferirle una carga vivífica en desmedro de su acepción destructiva. Sin embargo, en una desviación propia de un poeta fuerte con respecto a su precursor, Neruda efectúa lo que Harold Bloom, en su Ansiedad de la influencia, denomina Clinamen, al alejarse del idealismo teísta que se percibe en el itinerario poético whitmaniano a través del materialismo ateísta que sostiene a su obra.

Finalmente, a la luz del ensanchamiento epistémico que conlleva el estudio de la muerte en el análisis comparado de ambos poetas americanos, cabe destacar que la raíz panteísta común de ambas poéticas devela las consecuencias que conlleva para el significado de la vida la alteración semántica de la muerte. En efecto, el panteísmo permite reducir la realidad a una sinécdoque, toda

18 La riqueza de la obra poética nerudiana permite que convivan interpretaciones que, en ocasiones, son incluso antagónicas. En primer lugar, Alazraki veía una conexión escatológica de Neruda con los antiguos Upanishad y luego, Finlayson, con el budismo. Por mi parte, esta investigación conecta la obra de Neruda con el materialismo de un panteísmo ateo e, inversamente, el profesor Roberto Onell aventura que, en la sección 'Alturas de Macchu Picchu', el hablante lírico es Jesucristo en su destino de profeta que deviene mesías. Ambas posturas se contraponen, ya que en el caso de Onell se postula una trascendencia idealista-cristiana al amparo de una concepción dualista de la realidad (creador / creado). Esta investigación, en cambio, propone la lectura de una inmanencia materialista sobre la base de una concepción monista de la realidad en la que se diluye la categoría dualista y su estructura jerarquizada. 
vez que el todo puede ser designado por una de sus partes con las que tiene una relación de inclusión y viceversa. Se puede usar el nombre de Dios o El Alma (todo) para designar a una parte (hombre/mujer) y, a la inversa, usar el nombre del hombre o de la mujer para designar a Dios. De esta manera el ser humano se deifica en vida, con lo cual se produce una sobresaturación semántica de la vida al aumentar su carga vivífica hasta transformarla en una realidad sagrada. Con dicho tropo, la vida se diviniza y la muerte se anula, alterándose radicalmente la significación de dichas palabras. Rayano en lo esotérico, quizá Emerson y los poetas careados tuvieron la inaudita intención de entender la realidad como una figura retórica (diría Borges).

\section{BIBLIOGRAFÍA}

Alonso, Amado. Poesía y estilo de Pablo Neruda. Buenos Aires: Editorial Sudamericana, 1951. Barthes, Roland. El grado cero de la escritura. Buenos Aires: Siglo XXI Editores, 1973. Bloom, Harold. El canon occidental. Barcelona: Anagrama, 1997.

La ansiedad de la influencia. Una teoría de la poesía. Madrid: Editorial Trotta, 2009.

Borges, Jorge Luis. Introducción a la literatura norteamericana. Madrid: Alianza Editorial, 1999.

Cervantes, Sergio Alberto. "La filosofía trascendentalista de Emerson". Revista Clío, Facultad de Historia de la Universidad Autónoma de Sinaloa, vol. 5, N²1 (1997): 173-193.

Concha, Jaime. "Interpretación de Residencia en la Tierra de Pablo Neruda". Revista Mapocho, $\mathrm{N}^{\mathrm{o}}$ 2, tomo 1. Santiago: Editorial Universitaria (1963): 5-39. En línea.

Cortínez, Carlos. "La autoironía nerudiana”. Revista Chilena de Literatura N 43 (1993): 103-108.

Diccionario Akal de filosofia. Madrid: Akal, 2004.

Elliott, Jorge. Antología crítica de la Nueva Poesía Chilena (1957). Santiago: LOM Ediciones, 2002.

Emerson, Ralph Waldo. Naturaleza. Palma de Mallorca: José J. de Olañeta, Editor, 2007.

Ferrater, José. Diccionario de filosofia. Buenos Aires: Editorial Sudamericana, 1951.

Finlayson, Clarence. Escritos pensados. Santiago: Ediciones Universidad Diego Portales, 2006.

Goic, Cedomil. "Alturas de Macchu Picchu: la torre y el abismo", Anales de la Universidad de Chile, $\mathrm{N}^{\circ} 157-160$ (1971): 153-165.

Loyola, Hernán. "Lo que el más grande amor. Sobre Eros y Tánatos en Neruda". Atenea, No489 (2004).

Murphy, Francis. Walt Whitman. A critical anthology. Baltimore: Pinguin Books, 1969.

Neruda, Pablo. Antología. Santiago: Nascimento, 1970.

Canto general. Barcelona: Planeta, 1989. 
Canción de gesta y Las piedras de Chile. Buenos Aires: Sudamericana, 2004. Cantos ceremoniales y Plenos poderes. Buenos Aires: Sudamericana, 2004. Residencia en la Tierra. Santiago: Universitaria, 2009.

Onell, Roberto. La construcción poética de lo sagrado en "Alturas de Macchu Picchu” de Pablo Neruda. Hildesheim, Alemania: Georg Olms Verlag AG editor, 2016.

Paz, Octavio. El arco y la lira. El poema. La revelación poética. Poesía e historia. México: Fondo de Cultura Económica, 1986.

Los hijos del limo. Del romanticismo a la vanguardia. Santiago: Tajamar Editores Ltda., 2008.

Platón. Diálogos socráticos. México: Editorial Océano, 1999.

Rodríguez, Mario. "El tema de la muerte en 'Alturas de Macchu Picchu' de Pablo Neruda". Anales de la Universidad de Chile 131 (1964): 23-50.

Salerno, Nicolás. "Neruda: sus críticos y sus biógrafos". Revista del Centro de Estudios Públicos 94 (2004).

Sicard, Alain. El pensamiento poético de Pablo Neruda. Madrid: Editorial Gredos, 1981. “ 'Camerado' Neruda (apuntes sobre Walt Whitman y Pablo Neruda)”. Anales de Literatura Chilena 13 (2010): 183-194.

Tamayo, Juan José. Nuevo diccionario de teología. Madrid: Editorial Trotta, 2005.

Vendler, Helen. Poets Thinking: Pope, Whitman, Dickinson, Yeats. First Harvard University press paperback edition, 2006.

Whitman, Walt. Hojas de hierba. Barcelona: Lumen, 1997. 